This is a post-peer-review, pre-copyedit version of an article published in Nature Climate Change. The final authenticated version is available online at: https://doi.org/10.1038/s41558-020-00975-7

Accepted version downloaded from SOAS Research Online: http://eprints.soas.ac.uk/34661

\title{
Plausible energy demand patterns in a growing global economy with climate policy
}

\author{
November 2020
}

Gregor Semieniuk ${ }^{\mathrm{a}}$, Lance Taylor ${ }^{\mathrm{b}}$, Armon Rezai ${ }^{\mathrm{c}}$, and Duncan Foley ${ }^{\mathrm{d}}$

Reducing energy demand has become a key mechanism for limiting climate change, but practical limitations associated with large energy savings in a growing global economy and, importantly, its lower-income parts remain. Using new energy-GDP data, we show that adopting the same near-term low-energy growth trajectory in all regions in IPCC scenarios limiting global warming to $1.5^{\circ} \mathrm{C}$ presents an unresolved policy challenge. We discuss this challenge of combining energy demand reductions with robust income growth for the $\mathbf{6 . 4}$ billion people in middle and low income countries in light of economic development's reliance on industrialisation. Our results highlight the importance of addressing limits to energy demand reduction in integrated assessment modelling when regional economic development is powered by industrialisation and instead exploring faster energy supply decarbonisation. Insights from development economics and other disciplines could help generate plausible assumptions given the financial, investment and stability issues involved.

Limiting global warming to $2^{\circ} \mathrm{C}$ or even $1.5^{\circ} \mathrm{C}$ requires carbon emissions from energy to reach net zero by around mid-century ${ }^{1}$. Reducing energy demand is considered a key mechanism for emissions reduction and alleviates the burden on the two other principal measures: decarbonisation of the energy supply, and carbon dioxide removal (CDR $)^{2}$. However, energy is key for the economy. The implications for global and regional economic growth of reducing energy demand are insufficiently explored but central in integrated assessment models (IAMs).

Scenarios from IAMs synthesized in the IPCC Special Report on Global Warming of $1.5^{\circ} \mathrm{C}$ assume that absolute decoupling (i.e. reducing energy consumption while growing GDP) is both readily feasible and inexpensive ${ }^{3}$. The report presents 90 scenarios limiting the temperature increase to $1.5^{\circ} \mathrm{C}$ by 2100 . In the near term, all continue or exceed historically

\footnotetext{
a University of Massachusetts Amherst, and SOAS University of London. Corresponding author: gsemieniuk@umass.edu

${ }^{\mathrm{b}}$ New School for Social Research

c Vienna University of Economics and Business, International Institute for Applied Systems Analysis (IIASA), and Vienna Institute for International Economic Studies (WIIW)

${ }^{d}$ New School for Social Research
} 
observed GDP growth rates. However, the scenarios assume declining primary energy (PE) demand in contrast to historical patterns, with median global PE demand falling by $13.6 \%$ between 2020 and 2030 to a rate of $507.5 \mathrm{EJ} / \mathrm{yr}$ or $16.1 \mathrm{TW}$, below the level of 2010 . Some of this reduction is achieved by shifting from fossil to more efficient renewable energy sources. The resulting decarbonisation would be insufficient for meeting the $1.5^{\circ} \mathrm{C}$ constraint, so scenarios also require final energy (FE) demand to fall by a median $8.0 \%$ over the same period. Once decarbonisation is sufficiently advanced and/or CDR technologies become costcompetitive after 2040, energy demand is projected to return to its historical growth trend. These patterns are less pronounced, but qualitatively similar, in scenarios limiting temperature rise to $2^{\circ} \mathrm{C}$.

How plausible are these near-term projections? Economic growth-energy trajectories of rich, de-industrialising countries can be argued to decouple, at least from territorial energy demand ${ }^{4}$. But a large majority (84\%) of the global population currently lives in low and middle income countries which are still set on a development path paved by industrialisation. Using a new global dataset on national output-energy relationships from 1950 to the present, we discuss why decoupling trends contained in the current scenarios are hard to justify for robustly growing developing countries and explore how the underlying models' explanatory power could be improved. Focusing on the extreme case of the (relatively low-income) Middle East and Africa region, we illustrate that scenario assumptions about decoupling, catchingup, and energy demand (e.g. that per capita FE demand is projected to fall, often below levels deemed critical for decent living standards, while income growth accelerates) imply a nearterm mitigation capacity qualitatively similar to that of rich countries and a development path at odds with historical data and insights from development economics. While large efficiency improvements are thermodynamically possible, achieving the projected absolute decoupling alongside successful industrialisation presents an unresolved policy challenge. Growth strategies, financing of investments in capital constrained developing countries, means of technology transfer, and macroeconomic policy could facilitate both. Spelling them out explicitly could clarify lower limits on energy demand in growing economies and help uncover opportunities for modelling faster energy supply decarbonisation.

\section{Economic Activity and Energy Demand}

The dependence of economic output on energy can be expressed by decomposing GDP per capita (or labour productivity), Y/P, often seen as a measure of affluence, into energy per capita, E/P, and the inverse of energy intensity or energy 'productivity' of output in economists' jargon, $\mathrm{Y} / \mathrm{E}$, 


$$
\frac{Y}{P}=\frac{Y}{E} \frac{E}{P}
$$

This is an economically-inspired decomposition ${ }^{5}$ related to the widely used Kaya identity. ${ }^{6}$ Labour productivity growth requires either a decline in energy intensity (higher average energy productivity) or more energy per worker. Because energy enters the economy as primary energy (PE) and becomes final energy (FE) before acting directly on producing value as useful energy (UE), (1) can be further decomposed into

$$
\frac{Y}{P}=\frac{Y}{U E} \frac{U E}{F E} \frac{F E}{P E} \frac{P E}{P}
$$

where first law conversion efficiencies determine how much PE input is needed for a given useful energy output. Exergy or second law efficiency imposes upper bounds on these conversion ratios and thus a lower bound on energy intensity at every level.

Reducing energy demand is different from decarbonising its supply: there is no particular reason why the economy cannot run on a $100 \%$ decarbonised energy mix. However, thermodynamics explains why a minimum of energy must be involved in all productive human activity. Primary to final energy conversion efficiencies can be vastly improved when decarbonising the energy supply, and its magnitude is partly an accounting question. ${ }^{7}$ The pivot is the final to useful conversion efficiency, for which large theoretical and also significant technical potentials for improvement exist. ${ }^{8,9}$ The pertinent obstacles in a socio-economic context however are economic and behavioural, i.e. practical, limits to the rate at which efficiency improvements can be implemented in growing and developing economies, whose primary aim is to raise labour productivity and income per capita, not to improve energy efficiency.

\section{Historical trends}

The relationship between economic activity and energy demand has been widely analysed (see supplementary note 1). Historically, primary to final and useful conversion efficiencies have improved, but slowly. The useful energy to output ratio has no time trend ${ }^{10}$. Therefore, most labour productivity growth over the past three centuries translated into higher PE demand $^{11-14}$. Since the Industrial Revolution humans unlocked the energy stored in fossil fuels and power increasing amounts of useful labour human workers perform ${ }^{15,16}$. Labour productivity rose twentyfold between 1820 and the end of the millennium in Europe and its Western offshoots ${ }^{17}$. Most other countries have since embarked on the same process of energy-intensive technical change, aspiring to similar increases in labour productivity and the resulting standards of living. Economic historians mostly track correlations in GDP and primary energy per capita ${ }^{16}$, although recent work tentatively confirms similar patterns for final and useful energy demand ${ }^{10,18,19}$. 
105

106

107

108

109

110

111

112

113

114

115

116

117

118

119

120

121

122

123

124

125

126

127

128

129

130

131

132

133

134

135

136

137

138

139

140

141

[Figure 1 about here]

The relationship between energy demand and labour productivity is clearly visible in historical data. Figure 1a depicts annual time series for 185 countries over a period 1950-2014, comprising $\sim 99 \%$ of global population in most years, on a log-log scale. It reveals a very tight correlation between GDP per capita and PE per capita, with a Spearman rank correlation coefficient of 0.86 for the overall sample. While country-specific differences exist due to geography, climate, institutions, idiosyncratic production and consumption patterns etc., pooled data show that increases in GDP/capita go in hand with increases in PE/capita, both across countries and time. A flexible regression gives a nearly linear fit in the log-log plot over the interval relevant to today's developing countries. The estimated GDP elasticity of primary energy, i.e. the logarithmic derivative of primary energy divided by that of GDP, is 0.89 over the interval of USD 2,000 to USD 20,000 in 2011 purchasing power parity (a country belongs to the high-income group from a GDP of around USD 12,500 per capita). In other words, a $10 \%$ increase in GDP/capita corresponds to a $8.9 \%$ increase in PE/capita (see Methods), with the difference capturing the gradual reductions of primary energy intensity, PE/GDP, over time $^{20}$. The regression line flattens at very low levels suggesting a minimum level of energy use even when large parts of the economy operate in non-market subsistence activities or during (civil) war, e.g. the leftmost observations in the plot capture Liberia's first civil war. Data points above USD 130,000 are small oil exporting countries, introducing strong idiosyncrasies to the regression at such income levels. Our findings are robust to relevant subsamples (e.g. only large economies, the G20) and to alternative measures of GDP and population (extended data figure 1 , see also supplementary note 2 ).

Globally, labour productivity and per capita energy demand have been growing over the complete sample, except for periods of crisis. Figure $1 \mathrm{~b}$ divides global rates of change of GDP and PE/capita into three subperiods, corresponding to economic growth performance. The fastest global labour productivity growth on record occurred during 1950-73, known as the Golden Age of Capitalism (Gold) ${ }^{17}$. Rapid economic expansion was underpinned by an almost equally rapid growth in energy demand in particular for cheap oil and electricity; and rural electrification in many developing countries started virtually from scratch ${ }^{21,22}$. The Golden Age was followed by a period of crises and slow growth for the rest of the $20^{\text {th }}$ century (Slow). ${ }^{17}$ Sluggish GDP growth during the 1973 and 1978-9 oil crises preceded the deepest recession in 1981 the world had seen since the Great Depression. Deindustrialisation and productivity slowdown in rich countries combined with the transitions of formerly socialist economies, several of whom went through severe depressions, kept average growth rates lower 
142 throughout the 1980s-90s ${ }^{23}$. Higher energy prices and supply curtailment set in train energy 143 demand restraint and efficiency-increasing technological change in rich countries. Meanwhile,

144 the economic collapse of the Soviet Union forced a revision of its comparatively low efficiency 145 energy sector and production processes ${ }^{24}$. China's fast machinery upgrading combined with 146 a shift towards light industry in the 1980s-90s, temporarily slowed its energy demand growth 147 relative to that of $\mathrm{GDP}^{25}$. These one-time shifts produced an almost stagnant PE/capita 148 trajectory. After the millennium, growth in both measures rebounded, driven increasingly by 149 China's return to more energy intensive production, but also 'emerging markets' more 150 generally. Fast growth in both indicators was interrupted by the Great Recession 2008-09. 151 Growth rates subsequently returned to pre-millennium levels. Overall, faster growth in one 152 indicator was positively correlated with faster growth in the other, and PE demand growth was 153 a good proxy also for that of FE (extended data figure 2). And while energy demand in rich 154 countries has been stagnating and even falling, growth is continuing robustly in middle and 155 low income countries (figure 1c).

156

157 Future Scenarios

158 Stringent mitigation policy strives to break (some of) these historical trends. Scenarios of the 159 IPCC special report calculate that in order to achieve the $1.5^{\circ} \mathrm{C}$ goal, a structural break from 160 historical total energy-income relationships is needed in the coming twenty years. To characterize 161 this break, figure 2a combines future projections of GDP and FE/capita with aggregated 162 historical data from figure 1. The historical trend (black in figure 2a) is upwards and rightwards.

163 Extrapolations based on the three historical periods (red in figure 2a) continue in this direction: 164 faster economic growth in the Gold and Millennium periods (further right) is associated with 165 faster increases in energy demand (further up). In contrast, scenario pathways combine robust 166 growth in GDP/capita with an unprecedented sustained reduction in FE/capita, particularly in 167 the 2020s and 2030s. Qualitatively similar results hold for PE and for scenarios limiting 168 warming to $2^{\circ} \mathrm{C}$ (extended data figure 3 ).

\section{[Figure 2 about here]}

172 Four scenario pathways (blue in figure 2a), highlighted as so-called archetype scenarios in 173 the IPCC special report, are based on the shared socioeconomic pathways (SSP) 1, 2, and 5 174 and a 'low energy demand' (LED) scenario, which is also based on SSP2. Significant near175 term FE/capita reductions occur in all of them except SSP5, which assumes that current 176 carbon-intensive development is adopted globally and projects faster GDP/capita growth than 177 seen even during the Golden Age. Since other mitigation avenues are assumed to be 178 unavailable and/or exhausted, CDR is cost-effectively deployed to meet meaningful climate 
179 targets in SSP $5^{26}$. In SSP2 past technological, economic and social dynamics are extrapolated 180 and CDR is less cost-effective ${ }^{27}$. As a result, energy demand has to fall to meet the $1.5^{\circ} \mathrm{C}$ 181 target, with rates of energy intensity reductions surpassing previous records set in the 1980s182 90s. GDP/capita growth is robust, similar to the Millennium period average. The SSP1 "green 183 growth" scenario is optimistic by design and, therefore, least consistent with historical trends, 184 combining historically unobserved high GDP/capita growth rates with a $17 \%$ reduction in 185 FE/capita from 2020 to $2030^{28}$. The LED is a Goldilocks scenario with the same baseline as 186 SSP2, but with efficiency improvements and demand reductions due to consumer habits 187 following best practice in both the global South and North ${ }^{29}$. FE/capita falls by $32 \%$ from 2020 188 to 2030. This ensemble of scenarios unmistakably illustrates the clean break with past energy 189 drivers of economic growth underlying the $1.5^{\circ} \mathrm{C}$ and also $2^{\circ} \mathrm{C}$ targets.

190

191 This structural break extends to the regional level and is particularly striking for regions with 192 lower labour productivity, represented by the Middle East and Africa (MAF) region in figure 2b. 193 In this region, median GDP/capita growth and year across scenarios runs at healthy $2.5 \%$ 194 during 2020-2050, compared with stagnating 0.1\% during 1973-2000 and meagre 1.4\% during 195 2000-18. Since 1950, FE/capita has increased continuously in the MAF region, from less than $1960.4 \mathrm{~kW} /$ capita to around $1 \mathrm{~kW} /$ capita. This is low compared to the global average of $1971.75 \mathrm{~kW} /$ capita and lower still in some African countries, as the MAF average masks the large 198 variation between Middle Eastern oil exporters and sub-Saharan agrarian economies. 199 However, rather than converging toward the world average and in spite of the evidence that, 200 especially at these low levels, development (including GDP growth) and energy are 201 particularly strongly correlated, almost all scenarios project steep declines in FE demand for 202 the MAF region ${ }^{30}$. A majority of scenarios even move significantly below the $0.95 \mathrm{~kW} /$ cap 203 (30GJ/yr/cap) FE identified as tantamount to low levels of development in the SSP literature 204 itself ${ }^{31}$. The most extreme case sees a 56\% reduction from 2020 to 2030 to a rate of below $2050.5 \mathrm{~kW} /$ cap (supplementary note 3 details). Similar patterns are projected in Asia and to a 206 lesser extent Latin America (extended data figure 4 and supplementary note 4). Put differently, 207 the scenarios rely heavily on final to useful energy efficiency improvements to provide energy 208 services for development.

Mitigation strategies can also be characterized by comparing scenarios with their own baselines in addition to historical evidence ${ }^{32}$. Figure $3 a$ documents the near-term deviation of growth rates in both baseline and policy scenarios from historical rates. Global archetype baselines (marked by disks) assume faster GDP/capita growth than historically observed in 
216 the period to 2030, correlated with faster FE/capita growth in all but the SSP1 baseline. The

217 MAF region is the only region where every archetype scenario baseline assumes FE/capita

218 growth to slow down and economic growth to accelerate, thereby assuming some decoupling

219 already in the baseline. Remarkably, near-term GDP/capita growth accelerates in every single

220 global baseline of successful mitigation scenarios (extended data figure 5). Regions see more

221 variation. A few regional baselines exclusively in Asia and the OECD feature lower economic

222 growth rates, with Asia slowing from fast historical ones. Regional baseline FE/capita often

223 correlates positively with faster economic growth, but sometimes slows already like in the MAF

224 archetypes. In sum, baselines project near-term economic development highly successful by

225 historical standards, often but not always correlated with faster global energy demand growth.

226 Several regions are assumed to decouple already in the baseline.

228 Mitigation is assumed to leave economic growth rates virtually unchanged from baselines

229 while energy demand plummets. Deviations from baselines are an order of magnitude larger 230 for final energy than GDP (figure 3b). This is independent of whether GDP is exogenous or 231 endogenous in the IAM used (extended data figure 6a). The MAF region exhibits the same 232 flexibility for energy demand reductions from baselines as other regions, despite its much 233 lower base level and in addition to the substantial savings already assumed in its baseline 234 scenarios. After 2040 growth rates approach their historical averages across all scenarios. As 235 decarbonisation advances and/or CDR measures come online, energy demand becomes a 236 lesser constraint on emissions. These effects are qualitatively similar but less pronounced in 237 scenarios limiting warming to below $2^{\circ} \mathrm{C}$ (extended data figures $5,6 \mathrm{~b}$ ). In sum, scenarios are 238 optimistic in two ways: baselines exhibit an acceleration of income growth, then mitigation 239 assumes a decoupling between energy demand and income. How can this optimism be 240 motivated?

242 Problems with regional absolute decoupling

243 While models behind the scenarios discussed above vary in their details about future trends, 244 they share the same theoretical approach to economy-energy modelling. Responses to 245 carbon prices are assumed to be efficient, smooth, and in principle arbitrarily large. Except for 246 differences in parameter values, high-, middle- and low-income economies are assumed to 247 follow the same model. Supplementary note 5 critically discusses the economic growth theory 248 behind IAMs.

250 Development economics tells a cautionary tale about assuming efficient growth without 251 explaining how it is achieved. The simple idea of "getting the prices right", by imposing high 252 corrective carbon prices or equivalent policies, must contend with two centuries of economic 
253

254

255

256

257

258

259

260

261

262

263

264

265

266

267

268

269

270

271

272

273

274

275

276

277

278

279

280

281

282

283

284

285

286

287

288

289

history. Achieving sustained and fast economic growth from low levels has been far from the norm since the 1950s, and where it has been achieved it was by industrialisation. Industrial production requires higher commercial energy inputs per worker than either (subsistence) farming or services, and industrialisation has historically tended to imply rising, not falling, commercial energy intensity ${ }^{33-35}$. Yet, in order to realise the robust growth rates projected for the less affluent regions and the world as a whole, some form of industrialisation has to take place. Achieving this industrialisation is difficult. Simultaneously maximising energy conversion efficiency as emphasized in the scenarios above poses an unresolved policy challenge.

In order to industrialize and adopt 'frontier' technology, developing countries have to import capital goods from rich country producers. This is especially true for the kind of energy-saving industrialisation envisioned by the IPCC scenarios. Industrialising countries face what are known as 'two gap' problems in development economics. The domestic lack of savings hinders investments (gap 1), and excessive trade deficits - e.g. from the need to import high efficiency capital goods - makes these investments even more expensive (gap 2$)^{36}$. To get around this financing dilemma, less efficient but cheaper and possibly domestically produced machines could be installed. This would however 'lock in' the lower level of efficiency for the machines' lifetimes ${ }^{37}$. Case studies of tapping vast energy efficiency potentials tend to describe situations where financing is not a constraint ${ }^{38}$, and how quickly or whether efficiency improvements pay for themselves is context-dependent ${ }^{39}$.

The capital constraint is accentuated when recognising the limited domestic resources available in most countries ${ }^{40}$. Incomes reported in purchasing power parity (PPP) inflate lower income countries' resources to reflect relatively cheap domestic purchases. However, to the extent that energy efficient products must be purchased internationally, market exchange rates count. In 2018 - and low-income countries had only 42\% the income in terms of US dollars at market exchange rates compared to PPP (USD4,967 vs. USD11,769 per capita). Borrowing internationally and in foreign currency to finance these investments is risky and costly, as a predominance of international finance can have destabilising effects. ${ }^{41,42}$ Shrewd macroeconomic policy in developing countries could help with improving economic conditions and enabling the financing. It must also stabilise economies that are disrupted by high carbon prices.

Abrupt and unanticipated changes in prices (energy or otherwise) have caused recessions with high unemployment by upending the original production structure based on a different set of prices. The aftermath of the 1978-79 oil crisis is one example of this. It also helped cause 
debt defaults in Latin American countries when their foreign debts denominated in dollars became more expensive in the wake of the US' hike in interest rates (Volcker shock) to deal with US price changes. Additionally, disruptions from price-focussed climate policy could cause asset stranding, default on debts, and a destabilisation of the financial system via these 'transition risks', another area that needs a macroeconomic policy response ${ }^{43,44}$. IAMs, originally designed for long-term analysis, assume smooth paths of adjustment given any price. Yet, as the short-term assumes crucial importance for ambitious mitigation, the question of how financing and macroeconomic stability in developing countries constrains model pathways requires scrutiny and insights from short-term (development) macroeconomics could inform assumptions about feasible industrial and stabilization policy ${ }^{45,46}$.

\section{Research Directions}

Economists have historically tended to be more bullish than other disciplines about the economy's ability to overcome resource constraints via substitution ${ }^{47,48}$. Yet, the smooth substitution in developing countries of vastly more energy efficient technologies over the next couple of decades alongside successful development implied by current climate policy scenarios in IAMs is challenging also by these standards. None of this even addresses rebound effects, which are poorly understood at the macroeconomic level but could be substantial $^{49}$, additional consumption at the extensive margin, such as first-time purchase of white goods ${ }^{50}$, or increased air-conditioning in a warming climate ${ }^{51}$. Historical evidence and development economics strongly suggest saving energy cannot play the role it is currently assigned in scenarios.

IAMs were designed to produce consistent long-run projections of the climate and the economy. With climate change accelerating and policy lagging behind, model scenarios are push the limits of feasibility in multiple domains to achieve stringent mitigation targets. Hence, such scenarios have to be interpreted as conditional explorations. However, we argue that various IAM scenarios ignore important institutional constraints, which we believe to be binding due to historical evidence. Since IAMs cannot test their results against data that is not yet generated, they must convince with strong explanatory power that their pathways are plausible ${ }^{32,52}$. Our analysis of the development of energy demand alongside robust economic growth across regions suggests that the details of near-term "development without energy" need to be better understood for making plausible assumptions. ${ }^{53}$

Key details would involve clarifying developing country growth strategies (particularly industrialisation) and their energy implications, as well as problems of financing and stabilization in the short-term. Taking industrialisation as a growth strategy seriously may 
327 challenge some of the assumptions about low energy growth as we argued here. But more 328 attention to explicit modelling of investment and its financing may loosen other constraints. 329 While daunting challenges also exist in decarbonising developing countries' energy mix, ${ }^{40}$ 330 robust investment-price decline relationships could highlight opportunities for faster energy 331 supply decarbonisation ${ }^{54}$, where IAMs have been shown to depict slow rates of change relative 332 to historical figures ${ }^{55-57}$.

333

334 First attempts to quantify global investments within IAMs ${ }^{46}$ and independent studies ${ }^{41,58,59}$ are 335 promising, and financing and risks to stability are also starting to be considered ${ }^{60}$. Research 336 on the political feasibility of such investments and potential trade-offs between different 337 mitigation policies has not yet produced robust evidence, but suggests that barriers may 338 exist ${ }^{61,62}$. With their rapid break from past patterns of growth in economic output and energy 339 inputs, the scenarios show just how difficult the challenge for a concerted policy effort is to 340 simultaneously sustain economic growth, redirect investments towards low-carbon 341 alternatives, improve policy cooperation and prevent rebound effects with price policies that 342 must nonetheless not be regressive. Detailing the process by which this happens would make 343 them even more helpful tools in the design and analysis of climate change mitigation.

344

\section{ENDNOTES}

349 Correspondence and requests for materials should be addressed to GS.

350 Acknowledgements: LT and DF acknowledge support from the Institute for New Economic 351 Thinking.

352 Author contributions: LT conceived of and designed the experiments. GS performed the 353 experiments. All authors jointly analyzed the data, contributed to policy analysis and paper 354 writing.

355 Competing interests: The authors declare no competing interests. 
356

357

358

359

360

361

362

363

364

365

366

367

368

369

370

371

372

373

374

375

376

377

378

379

380

381

382

383

384

385

386

387

388

389

390

391

392

\section{Bibliography}

1. Rogelj, J. et al. Scenarios towards limiting global mean temperature increase below $1.5^{\circ}$ C. Nat. Clim. Chang. 8, 325-332 (2018).

2. Vuuren, D. P. Van et al. Carbon budgets and energy transition pathways. Environ. Res. Lett. 11, 075002 (2016).

3. Rogelj, J. et al. Mitigation Pathways Compatible with $1.5^{\circ} \mathrm{C}$ in the Context of Sustainable Development. in Global warming of $1.5^{\circ} \mathrm{C}$. An IPCC Special Report on the impacts of global warming of $1.5^{\circ} \mathrm{C}$ above pre-industrial levels and related global greenhouse gas emission pathways, in the context of strengthening the global response to the threat of climate change, (eds. Masson-Delmotte, V. et al.) (Cambridge University Press, 2018).

4. Akizu-Gardoki, O. et al. Hidden Energy Flow indicator to reflect the outsourced energy requirements of countries. J. Clean. Prod. 278, 123827 (2021).

5. Taylor, L. Energy Productivity, Labor Productivity, and Global Warming. in TwentyFirst Century Macroeconomics. Responding to the Climate Challenge (eds. Harris, J. \& Goodwin, N.) (Elgar, 2009).

6. Nakićenović, N. et al. Special Report on Emissions Scenarios. (Cambridge University Press, 2000).

7. Koomey, J., Schmidt, Z., Hummel, H. \& Weyant, J. Inside the Black Box: Understanding key drivers of global emission scenarios. Environ. Model. Softw. 111, 268-281 (2019).

8. Cullen, J. M., Allwood, J. M. \& Borgstein, E. H. Reducing energy demand: What are the practical limits? Environ. Sci. Technol. 45, 1711-1718 (2011).

9. Nakićenović, N., Gilli, P. V. \& Kurz, R. Regional and global exergy and energy efficiencies. Energy 21, 223-237 (1996).

10. Serrenho, A. C., Warr, B., Sousa, T. \& Ayres, R. U. Structure and dynamics of useful work along the agriculture-industry-services transition : Portugal from 1856 to 2009. Struct. Chang. Econ. Dyn. 36, 1-21 (2016).

11. Smil, V. Energy in World History. (Westview Press, 1994).

12. Crosby, A. W. Children of the sun : a history of humanity's unappeasable appetite for energy. (W.W. Norton, 2006).

13. Fouquet, R. A brief history of energy. in International Handbook of the Economics of Energy (eds. Evans, J. \& Hunt, L. C.) (Edward Elgar, 2009).

14. O'Connor, P. A. \& Cleveland, C. J. U.S. energy transitions 1780-2010. Energies 7, 7955-7993 (2014).

15. Wrigley, E. A. Energy and the English Industrial Revolution. (Cambridge University Press, 2010). doi:DOI: 10.1017/CBO9780511779619 
393

394

395

396

397

398

399

400

401

402

403

404

405

406

407

408

409

410

411

412

413

414

415

416

417

418

419

420

421

422

423

424

425

426

427

428

429

16. Kander, A., Malanima, P. \& Warde, P. Power to the people : energy in Europe over the last five centuries. (Princeton University Press, 2013).

17. Maddison, A. The World Economy: A Millennial Perspective. (OECD, 2001).

18. Fouquet, R. Heat, Power and Light: Revolutions in Energy Services. (Edward Elgar Publishing Limited, 2008).

19. De Stercke, S. Dynamics of Energy Systems: a Useful Perspective. IIASA Interim Rep. IR-14-013,

20. Csereklyei, Z., Rubio-Varas, M. d. M. \& Stern, D. I. Energy and Economic Growth: The Stylized Facts. Energy J. 37, 223-255 (2016).

21. UN ECAFE. Rural Electrification. United Nations Publ. E/CN.11/39, (1954).

22. Fouquet, R. Historical energy transitions: Speed, prices and system transformation. Energy Res. Soc. Sci. 22, 7-12 (2016).

23. Semieniuk, G. Energy in Economic Growth: Is Faster Growth Greener? SOAS Dep. Econ. Work. Pap. Ser. 208, (2018).

24. Dienes, L., Dobozi, I. \& Radetzki, M. Energy and Economic Reform in the Former Soviet Union. (Macmillan, 1994).

25. Zhang, Z. X. Why did the energy intensity fall in China's industrial sector in the 1990s? The relative importance of structural change and intensity change. Energy Econ. 25, 625-638 (2003).

26. Kriegler, E. et al. Fossil-fueled development ( SSP5 ): An energy and resource intensive scenario for the 21st century. Glob. Environ. Chang. 42, 297-315 (2017).

27. Fricko, O. et al. The marker quantification of the Shared Socioeconomic Pathway 2: A middle-of-the-road scenario for the 21st century. Glob. Environ. Chang. 42, 251-267 (2017).

28. Vuuren, D. P. Van et al. Energy, land-use and greenhouse gas emissions trajectories under a green growth paradigm. Glob. Environ. Chang. 42, 237-250 (2017).

29. Grubler, A. et al. A low energy demand scenario for meeting the $1.5^{\circ} \mathrm{C}$ target and sustainable development goals without negative emission technologies. Nat. Energy 3, 515-527 (2018).

30. Vita, G., Hertwich, E. G., Stadler, K. \& Wood, R. Connecting global emissions to fundamental human needs and their satisfaction. Environ. Res. Lett. 14, (2019).

31. Bauer, N. et al. Shared Socio-Economic Pathways of the Energy Sector - Quantifying the Narratives. Glob. Environ. Chang. 42, 316-330 (2017).

32. Schwanitz, V. J. Evaluating integrated assessment models of global climate change. Environ. Model. Softw. 50, 120-131 (2013).

33. Nielsen, H., Warde, P. \& Kander, A. East versus West: Energy intensity in coal-rich Europe, 1800-2000. Energy Policy 122, 75-83 (2018). 
430

431

432

433

434

435

436

437

438

439

440

441

442

443

444

445

446

447

448

449

450

451

452

453

454

455

456

457

458

459

460

461

462

463

464

465

466

34. Appleby, P., Fennema, J., Naumov, A., Schaffer, M. \& Christof, R. Economic development and the demand for energy : A historical perspective on the next 20 years. 50, 109-116 (2012).

35. Ocampo, J. A., Rada, C. \& Taylor, L. Growth and Policy in Developing Countries. (Cambridge University Press, 2009).

36. Taylor, L. Gap models. J. Dev. Econ. 45, 17-34 (1994).

37. Fouquet, R. Path dependence in energy systems and economic development. Nat. Energy 1, (2016).

38. Lovins, A. B. How big is the energy efficiency resource? Environ. Res. Lett. 13, 090401 (2018).

39. Fowlie, M., Greenstone, M. \& Wolfram, C. Do Energy Efficiency Investments Deliver? Evidence from the Weatherization Assistance Program. Q. J. Econ. 133, 1597-1644 (2018).

40. Rozenberg, J., Davis, S. J., Narloch, U. \& Hallegatte, S. Climate constraints on the carbon intensity of economic growth. Environ. Res. Lett. 10, (2015).

41. UNCTAD. Trade and Developmnet Report 2019: Financing a Global Green New Deal. (United Nations Conference on Trade and Development, 2019).

42. Bresser-Pereira, L., Oreiro, J. \& Marconi, N. Developmental Macroeconomics. (Routledge, 2014). doi:https://doi.org/10.4324/9780203583500

43. Semieniuk, G., Campiglio, E., Mercure, J.-F., Volz, U. \& Edwads, N. Low-carbon transition risks for finance. WIREs Clim. Chang. In press, (2020).

44. Battiston, S., Mandel, A., Monasterolo, I., Schütze, F. \& Visentin, G. A climate stresstest of the financial system. Nat. Clim. Chang. 7, 283-288 (2017).

45. Kriegler, E. et al. Short term policies to keep the door open for Paris climate goals. Environ. Res. Lett. 13, (2018).

46. McCollum, D. L. et al. Energy investment needs for fulfilling the Paris Agreement and achieving the Sustainable Development Goals. Nat. Energy 3, 589-599 (2018).

47. Foley, D. K. Dilemmas of economic growth. East. Econ. J. 38, 283-295 (2012).

48. Solow, R. M. Is the End of the World at Hand? Challenge 16, 39-50 (1973).

49. van Benthem, A. A. Energy Leapfrogging. J. Assoc. Environ. Resour. Econ. 2, 93-132 (2015).

50. Wolfram, C., Shelef, O. \& Gertler, P. How Will Energy Demand Develop in the Developing World? J. Econ. Perspect. 26, 119-138 (2012).

51. Davis, L. W. \& Gertler, P. J. Contribution of air conditioning adoption to future energy use under global warming. Proc. Natl. Acad. Sci. 112, 5962 LP - 5967 (2015).

52. Anderson, K. \& Jewell, J. Debating the bedrock of climate-change mitigation scenarios. Nature 573, 348-349 (2019). 
467

468

469

470

471

472

473

474

475

476

477

478

479

480

481

482

483

484

485

486

487

488

489

490

491

53. Steckel, J. C., Brecha, R. J., Jakob, M., Strefler, J. \& Luderer, G. Development without energy? Assessing future scenarios of energy consumption. Ecol. Econ. 90, 53-67 (2013).

54. Nagy, B., Farmer, J. D., Bui, Q. M. \& Trancik, J. E. Statistical Basis for Predicting Technological Progress. PLoS One 8, 1-7 (2013).

55. Wilson, C., Grubler, A., Bauer, N., Krey, V. \& Riahi, K. Future capacity growth of energy technologies: are scenarios consistent with historical evidence? Clim. Change 118, 381-395 (2013).

56. Creutzig, F. et al. The underestimated potential of solar energy to mitigate climate change. Nat. Energy 2, (2017).

57. Mohn, K. The Gravity of Status Quo: A Review of IEA's World Energy Outlook. Econ. Energy Environ. Policy 9, 63-81 (2020).

58. Rezai, A., Taylor, L. \& Foley, D. K. Economic Growth, Income Distribution, and Climate Change. Ecol. Econ. 146, 164-172 (2018).

59. Pollin, R. Greening the Global Economy. in (MIT Press, 2015).

60. Battiston, S., Monasterolo, I., Riahi, K. \& van Ruijven, B. J. Climate mitigation pathways need to account for the ambivalent role of finance. Manuscr. Prep. (2020).

61. Patt, A., van Vliet, O., Lilliestam, J. \& Pfenninger, S. Will policies to promote energy efficiency help or hinder achieving a $1.5^{\circ} \mathrm{C}$ climate target? Energy Effic. 12, 551-565 (2019).

62. Jewell, J. \& Cherp, A. On the political feasibility of climate change mitigation pathways: Is it too late to keep warming below $1.5^{\circ} \mathrm{C}$ ? WIREs Clim. Chang. 11, e621 (2020). 


\section{Methods:}

\section{Historical Country Data}

The historical analysis builds on a newly compiled dataset for annual national total primary energy supply from 1950 to 2014 with nearly global coverage of 186 countries. Total primary energy supply from the International Energy Agency Energy Balances ${ }^{63}$ (starting in 1960 for most OECD countries, and 1971 or later for other countries) was combined with Energy Balances constructed from the United Nations Energy Statistics ${ }^{64}$ that start in 1950. IEA data was converted to direct equivalent accounting for compatibility with UN data and IPCC scenarios, all of which use that accounting method. Where both datasets were available, IEA data was used; however, besides wide coverage back to 1950, the UN data covers several countries not included in the IEA data. Databases were spliced and adjusted to the IEA level if necessary. To address the problem of missing non-commercial energy data (most often reported only from 1970 by the UN), non-commercial energy demand in most areas of the world in 1949 was taken from a unique 1952 study by the $U N^{65}$. The share of non-commercial energy in the mix in 1949 and 1970 or the earliest available year was calculated and the share in each year in the interval interpolated. Then total primary energy supply was calculated by adding the non-commercial energy demand implied by the interpolated share to the known commercial energy supply. GDP and population are from the Penn World Table ${ }^{66}$ and, where unavailable, from the Maddison Project ${ }^{67}$. Supplementary figure 1 shows the resulting population and country coverage. The 1950 s cover upwards of $91 \%$ of population, and this coverage reaches almost $98 \%$ in the 1960s and stays above 99\% from 1971 onwards. Between 1969 and 1971 many additional countries report data, but most of the 1990 additions are due to accounting switching from the former Soviet Union and Yugoslavia to altogether 20 successor states. Detail about the dataset construction, in particular the construction of noncommercial energy time series and treatment of dissolving or unifying countries is in the accompanying data article ${ }^{68}$.

\section{Historical Regional Data}

Historical world and regional primary and final energy, GDP and population data are from the IEA Energy Balances and Indicators from 1971 through 2017. Countries were assigned to regions according to the IPCC's R5 definition ${ }^{69}$. Data for the world for 2018 are from IEA's 2019 World Energy Outlook ${ }^{70}$ and the World Bank Open Data. Primary energy was converted to direct equivalent accounting for comparability with IPCC scenarios. For 1950-1970 regional data and global energy data is from the PFU database ${ }^{19}$, global population data is from the UN, GDP data for 1960-1971 is from the World Bank and for 1950-1960 from the Maddison Project. These data were spliced and adjusted to the level of the later time series where necessary. 
530

531

532

533

534

535

536

537

538

539

540

541

542

543

544

545

546

547

548

549

550

551

552

553

554

555

556

557

558

559

560

561

562

563

\section{Historical Correlation and Regression Analysis}

\section{The correlation coefficient calculated for historical data is Spearman's rank-based} coefficient. Figure 1 in the main text displays a local polynomial regression, loess, which does not impose a particular parametric global model, but estimates a fit based on segments of the data using a quadratic polynomial. For each observation $j=1, \ldots n$, we estimate an equation system of $k=0.8 \times n$ dimensions

$$
\frac{E_{i}}{P_{i}}=\alpha+\beta_{1} \frac{Y_{i}}{P_{i}}+\beta_{2}\left(\frac{Y_{i}}{P_{i}}\right)^{2}+\varepsilon_{i}, \quad \text { for } i=1, \ldots k
$$

using least squares, and including observation j and its argument's k-1 nearest neighbours, that are weighted in the least squares calculation using the tricubic function $w=\left(1-|d|^{3}\right)^{3}$ and where $d$ is a metric distance between observation $\mathrm{j}$ and its neighbours. This gives $\mathrm{n}$ fits. In the plot, each dot is the predicted value $\frac{\widehat{E_{l}}}{P_{l}}$ at argument $\frac{Y_{i}}{P_{i}}$ of the $\mathrm{i}^{\text {th }}$ fit. Loess is introduced in Cleveland ${ }^{71}$ and for computation we use the $\mathrm{R}$ language implementation loess() $)^{72}$. The extended data fit to $\mathrm{G} 20$ countries uses a polynomial of degree one to account for the lower number of observations.

An elasticity of $\mathrm{y}$ with respect to $\mathrm{x}, \eta_{y, x}$, is defined as the percent change in $\mathrm{y}$ for a one percent change in $\mathrm{x}$ or the ratio of the logarithmic derivatives, $\eta_{y, x}=\frac{\partial \log y}{\partial \log x}$. We approximate elasticities of primary energy per capita with respect to output per capita by taking two arguments and their respective predicted values from the local polynomial regression and dividing the rates of change in both variables through each other

$$
\eta_{\bar{E}, \bar{P}}=\frac{\left(\frac{\widehat{E_{2}}}{P_{2}}-\frac{\widehat{E_{1}}}{P_{1}}\right) / \frac{\widehat{E_{1}}}{P_{1}}}{\left(\frac{Y_{2}}{P_{2}}-\frac{Y_{1}}{P_{1}}\right) / \frac{Y_{1}}{P_{1}}}
$$

\section{IPCC scenario data and analysis}

Data for the scenarios of the future pathways were downloaded on October 19, 2019 from the database behind the IPCC Special Report on Global Warming of $1.5^{\circ} \mathrm{C}$, version iamc15_scenario_data_all_regions_r2.0 $0^{73}$. The database was supplemented first with baselines for the 'PEP' suite of scenarios ${ }^{45}$ calculated with REMIND-MAgPIE 1.7-3.0, which are not included in the special report dataset. The PEP modelling team kindly shared the PEP baseline data upon request. Second, the database was supplemented with regional data for the Low Energy Demand (LED) scenario $^{29}$, which were not yet available at the time 
564 of the $1.5^{\circ} \mathrm{C}$ Warming IPCC report from 2018 , and have been kindly made available by the

565 LED modelling team upon request. In the resulting dataset, 90 scenarios achieve $1.5^{\circ} \mathrm{C}$

566 average global warming above preindustrial levels by 2100 with a $50 \%$ chance. Scenarios

567 are further subdivided by their probability of temporarily overshooting this temperature during

568 the $21^{\text {st }}$ century. 9 scenarios have a $50-66 \%$ chance not to overshoot in the $21^{\text {st }}$ century; 44

569 scenarios overshoot with a 50-67\% (low) chance; the remainder have a high probability

570 greater than $67 \%$ of overshoot ${ }^{3}$. Not all scenarios report both GDP and primary and final

571 energy. None of the five C-ROADS-5.005 scenarios report primary and final energy figures.

572 The only MERGE ETL 6.0 scenario and four REMIND 1.5 scenarios do not report GDP. This

573 leaves 80 scenarios, based on 7 models (which can have several versions), as depicted in

574 the supplementary table 1, with more than half of all scenarios supplied by two models. 79

575 scenarios report data on all indicators for MAF and REF regions, and ten of these, all from

576 the POLES model in the scenario family EMF33 do not report data for other regions, leaving

57769 models with full regional coverage. The table also shows how GDP is calculated. For

578 further information see the IPCC report's supplementary material, which also states the

579 historical period that the report used for validation of energy-GDP trajectories to be 1971-

$5802015^{74}$. This period can differ from the periods used when individual scenarios were

581 published. E.g. the MESSAGE SSP2 archetype uses 1970-2010 ${ }^{27}$ and the SSP energy

582 sector overview considers $1980-2010^{31}$.

583 The database also contains 119 scenarios limiting warming to $2^{\circ} \mathrm{C}$ and 185 scenarios,

584 including but not limited to baseline scenarios where global warming is above $2^{\circ} \mathrm{C}$ in 2100 .

585 To these correspond 109 and 179 scenarios with at least some regional details. These

586 scenarios form the ensemble of the scenarios investigated here.

587 To compare historical levels with those in the scenarios in the main text's figure 2, all

588 scenarios were adjusted so that the GDP and energy per capita levels in 2010 were equal to

589 those of the historical data. Where actual energy demand levels are mentioned in the text,

590 these are taken from the original scenario data, not from the adjusted series.

591

592

\section{Data availability}

593 The data that support the national and regional historical energy series are from the United

594 Nations (UN) and the International Energy Agency (IEA) but restrictions apply to the

595 availability of these data, which were used under licence for the current study, and so are

596 not publicly available. National historical data are however deposited with the UK Data

597 Service ${ }^{68}$ with access conditional on case-by-case permission by the IEA:

598 https://www.ukdataservice.ac.uk/get-data.aspx. All other historical data is publicly available

599 from the Penn World Table, Maddison Project, the World Bank and the PFU database. The

600 data that support the future scenarios are derived exclusively from the IAMC $1.5^{\circ} \mathrm{C}$ Scenario 
601 Explorer and Data and are available for free at: https://data.ene.iiasa.ac.at/iamc-1.5c-

602 explorer/.

603

604

Code availability.

605 The code for curating the future scenario data once downloaded and for generating all the

606 figures in the paper is available with the authors on reasonable request. It is coded in R.

607

608

609

610

611

612

613

614

615

616

617

618

619

620

621

622

623

624

625

626

627

628

629

630

631

632

633

634

635

636

637

\section{References}

63. International Energy Agency. Word Energy Balances 2018. (International Energy Agency, 2018). doi:10.15713/ins.mmj.3

64. UN. The United Nations Energy Statistics Database. (United Nations Energy Statistics Division, 2016).

65 UN. World Energy Supplies in Selected Years, 1929-1950. United Nations Stat. Pap. Ser. J No. 1, (1952).

66. Feenstra, R. C., Inklaar, R. \& Timmer, M. P. The Next Generation of the Penn World Table. Am. Econ. Rev. 105, 3150-3182 (2015).

67. Bolt, J., Inklaar, R., de Jong, H. \& van Zanden, J. L. Rebasing 'Maddison': new income comparisons and the shape of long-run economic development. Maddison Proj. Work. Pap. 10 (2018).

68. Semieniuk, G. Primary energy demand and GDP per capita for most countries of the world, 1950-2014 [Data Collection]. (UK Data Service, 2020).

69. Krey, V. et al. Annex II: Metrics and Methodology. in Climate Change 2014: Mitigation of Climate Change. Contribution of Working Group III to the Fifth Assessment Report of the Intergovernmental Panel on Climate Change (eds. Edenhofer, O. et al.) (2014).

70. IEA. World Energy Outlook 2019. (International Energy Agency, 2019).

71. Cleveland, W. S. Robust Locally Weighted Regression and Smoothing Scatterplots. J. Am. Stat. Assoc. 74, 829-836 (1979).

72. Chambers, J. M. \& Hastie, T. J. Statistical Model in S. (Chapman and Hall, 1993).

73. Huppmann, D. et al. IAMC $1.5^{\circ} \mathrm{C}$ Scenario Explorer and Data hosted by IIASA. (2018). doi:https://doi.org/10.22022/SR15/08-2018.15429

74. Forster, P. et al. Mitigation Pathways Compatible with $1.5^{\circ} \mathrm{C}$ in the Context of Sustainable Development Supplementary Material. in Global Warming of $1.5^{\circ} \mathrm{C}$. An IPCC Special Report on the impacts of global warming of $1.5^{\circ} \mathrm{C}$ above pre-industrial levels and related global greenhouse gas emission pathways, in the context of strengthening the global response to the threat of climate change, (eds. MassonDelmotte, V. et al.) (2018). 
639 Figure 1 | Historical output and energy per capita relation: (a) Annual GDP per capita in

6402011 kiloUSD at purchasing power parity (PPP) and direct equivalent primary energy

641 including non-commercial sources per capita in kilowatt for 185 countries 1950-2014

642 (unbalanced). Every colour represents a country time series. The black line is a loess fit with

643 the blue lines 1.96 standard deviations. (b) Global annual and average growth rates during

644 three historical periods. (c) Rate of energy flow in countries grouped by GDP/capita, 1950-

645 2014. Sources: see Methods.

646

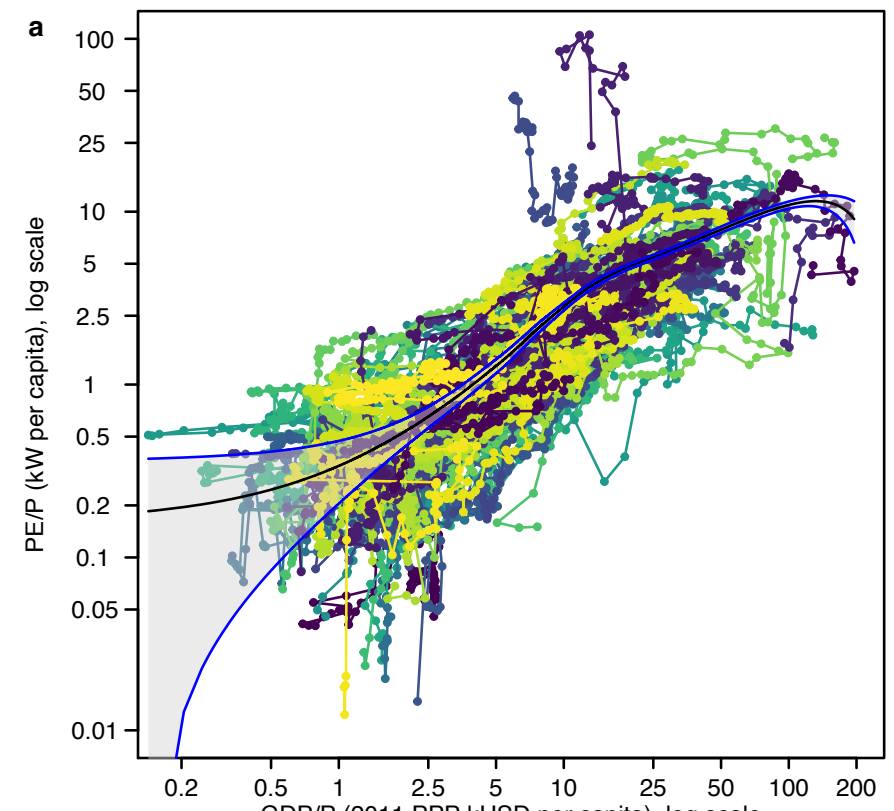

647
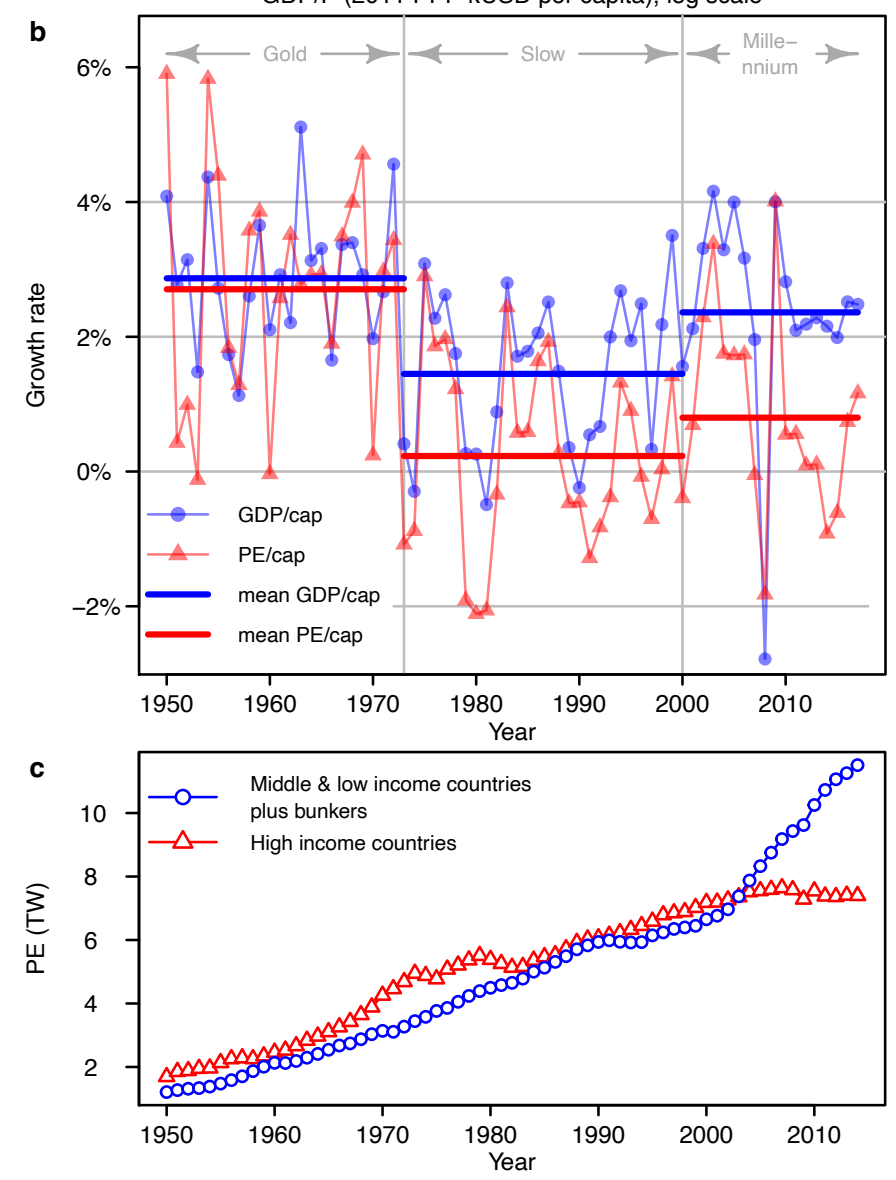
Figure 2 | Projections of output and final energy per capita relation until 2050: (a)

Global income per capita and final energy per capita projections of $1.5^{\circ} \mathrm{C}$ scenarios to 2050 in grey. Archetype scenarios are in blue, others in grey. Scenario values have been normalised to start at the same historical level in 2010. Markers indicate decades. The historical trajectory is in black and the red lines extrapolate 1950-73 (Gold), 1973-2000 (Slow) and 2000-18 (Millennium) growth rates. The Gold extrapolation is truncated after 2030 to avoid extending the y-axis. (b) Same as (a) but for Middle East \& Africa region. Sources: see methods.
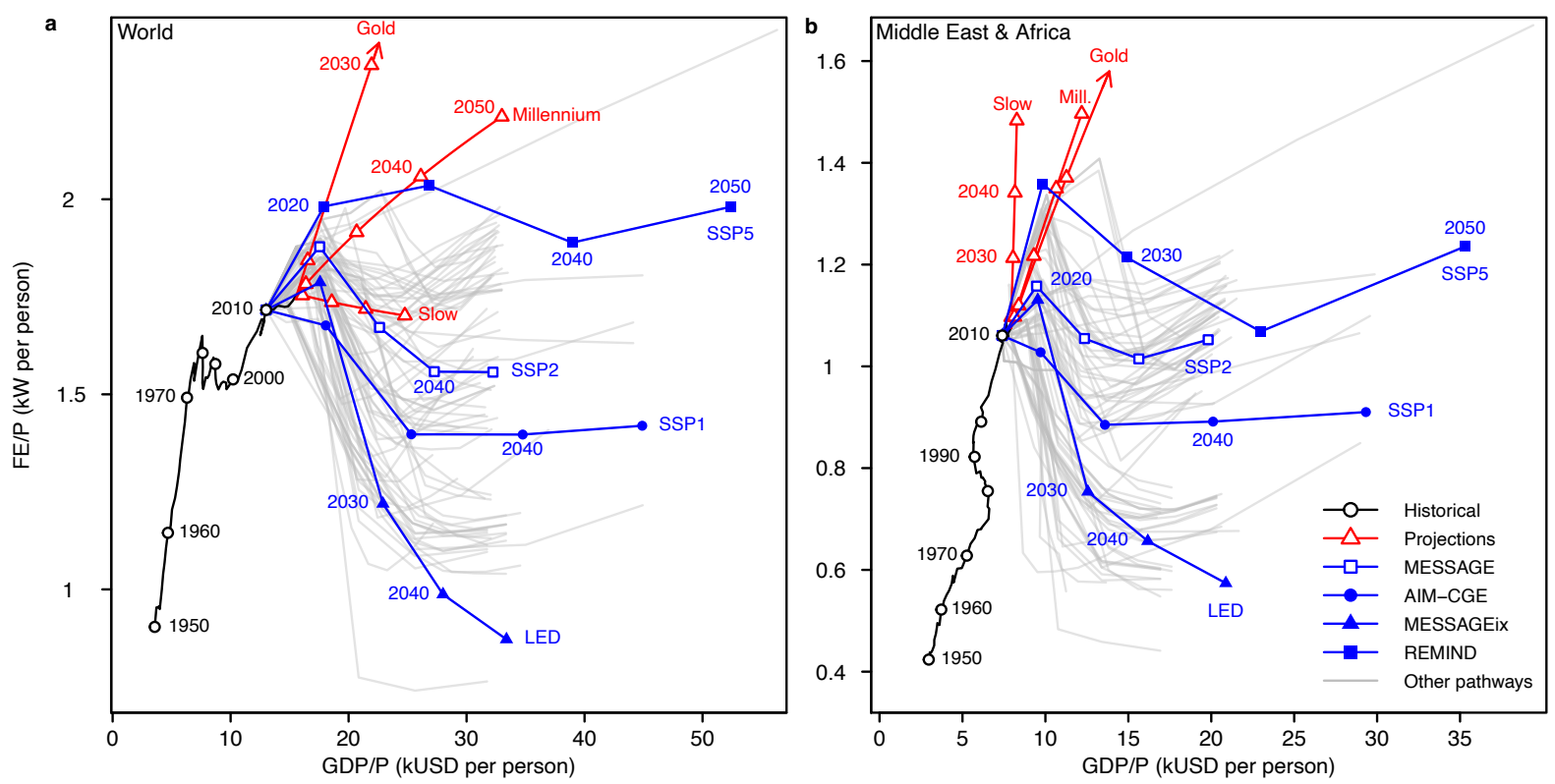
662

663

664

665

666

667

668

669

670

Figure 3 | Baseline and policy scenario growth rate deviations from historical rates:

(a) Growth rate deviation in percentage points in scenarios in 2020-30 relative to the 19702015 historical average for the World and Middle East \& Africa in baselines (BAU) and successive mitigation scenarios, $2^{\circ} \mathrm{C}$ and $1.5^{\circ} \mathrm{C}$ of the four SSP 'archetype' scenarios. GDP/capita deviation is on the x-axis, FE/capita is on the y-axis. (b) Deviations in percentage points from BAU growth rates in all scenarios mitigating to $1.5^{\circ} \mathrm{C}$ in three periods for the World and Middle East \& Africa. Boxes encompass the interquartile range with a horizontal line for the median, and have no whiskers.

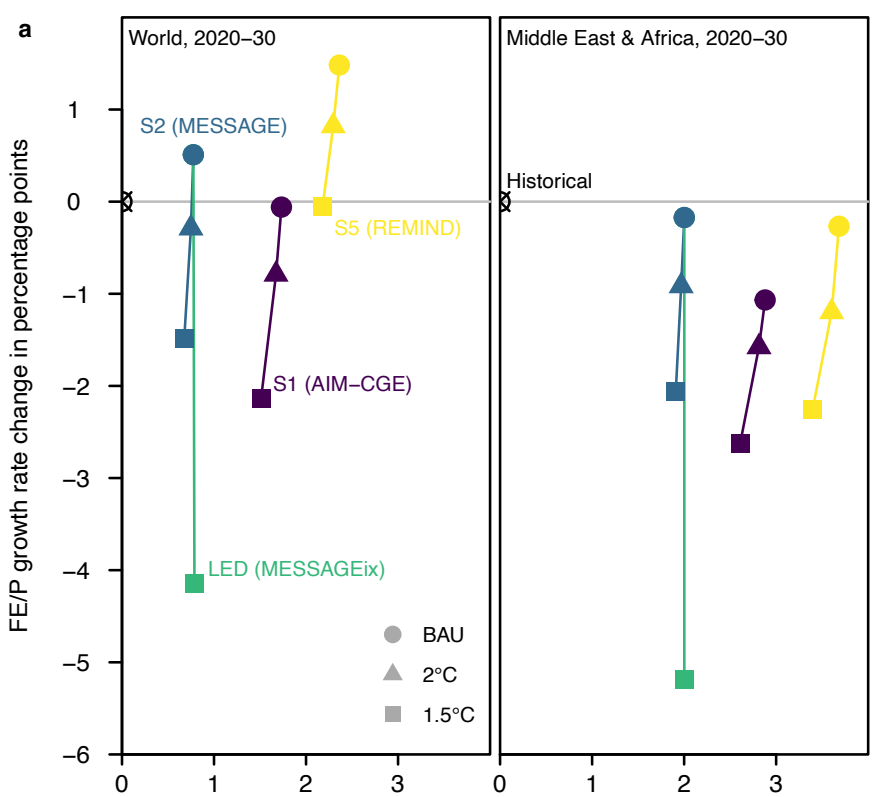

671

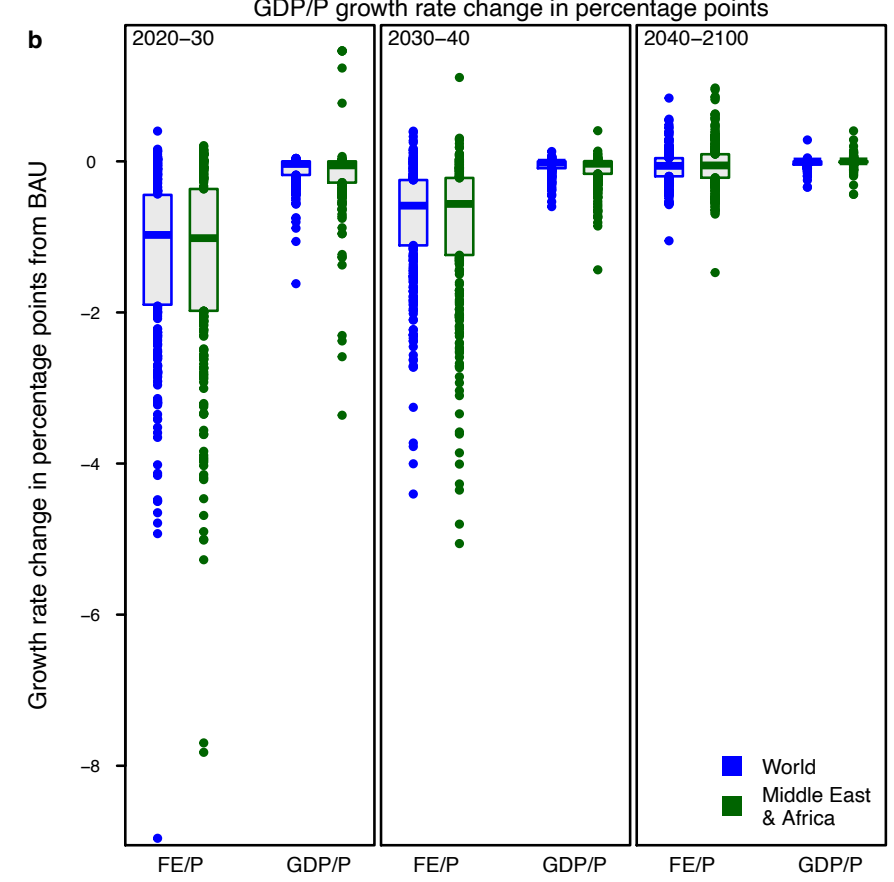

672 